\title{
PAPER
}

\section{Vertebral artery origin angioplasty and primary stenting: safety and restenosis rates in a prospective series}

\author{
G C Cloud, F Crawley, A Clifton, D J H McCabe, M M Brown, H S Markus
}

J Neurol Neurosurg Psychiatry 2003;74:586-590

See end of article for authors' affiliations

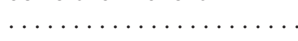

Correspondence to: Professor Hugh Markus, Division of Clinical Neuroscience, St George's Hospital Medical School Cranmer Terrace, London SW 17 ORE, UK:

h.markus@sghms.ac.uk

Received 30 July 2002

In revised form

3 December 2002

Accepted

11 January 2003

Objectives: To report a single centre ongoing experience of endovascular treatment for atherosclerotic
vertebral artery origin stenosis in a series of symptomatic patients, with follow up imaging to determine the incidence of restenosis.

Methods: 14 patients with vertebral artery origin stenosis on catheter angiography were treated. Angioplasty without stenting was undertaken in the first four patients, all of whom had follow up catheter angiography at one year. Subsequently, patients were treated by primary stenting and followed up with colour Doppler ultrasound examination.

Results: The procedure was technically successful in all treated arteries, with no immediate complications. The degree of stenosis was reduced from (mean (SD)) $73(18) \%$ before treatment to 21 (26)\% immediately after treatment in the angioplasty alone group $(p=0.059)$. In the primary stenting patients, the severity of stenosis was reduced from $82(8) \%$ to $13(13) \%$ immediately after treatment $(p<0.001)$. Restenosis to $70 \%$ or greater occurred at one year in all four patients initially treated by angioplasty without stenting. One patient subsequently developed further symptoms and was retreated by stenting. One of the 10 patients treated by primary stenting developed restenosis. None of the remaining patients had further posterior circulation ischaemic symptoms during a mean follow up period of 33.6 months (range 1 to 72 months).

Conclusions: Restenosis occurs often after vertebral artery origin balloon angioplasty without stenting but is uncommon after stenting. Primary stenting is therefore recommended to maintain patency at this site, and had a low complication rate in this series.

O ne quarter of strokes occur in the posterior circulation. ${ }^{12}$ Atherosclerotic stenosis of the vertebral artery most commonly occurs at the origin, ${ }^{3}$ and embolisation from such lesions is an important cause of posterior circulation stroke..$^{4-6}$ Approximately one in five posterior circulation strokes occurs in the setting of extracranial vertebral artery stenosis, ${ }^{4}$ but the optimal management of such patients is unclear.

Carotid endarterectomy is widely used for the treatment of extracranial symptomatic carotid artery stenosis, but vertebral artery stenosis is often managed by medical treatment alone. Surgery for extracranial vertebral artery stenosis, in the form of endarterectomy and vessel revascularisation (bypass or transposition), has been reported to be associated with good outcome and low mortality. ${ }^{8-11}$ However, such operations are not widely undertaken because it is difficult to gain access to the vertebral artery at its origin.

Percutaneous endovascular treatment of vertebral artery stenosis is much less invasive than surgery and could prevent recurrent embolic or haemodynamic symptoms in this patient group. The carotid and vertebral artery transluminal angioplasty study (CAVATAS) showed a similar risk of stroke or death with endovascular treatment and surgery within 30 days after the procedure, in patients with severe symptomatic carotid artery stenosis. ${ }^{12}$ The two treatment modes also appeared equally effective at preventing ipsilateral stroke, or death and disabling stroke, in any vascular territory for up to three years after randomisation.

To date, at least 5210 carotid angioplasty and stenting procedures in 4757 patients have been reported, with an overall technical success rate of $98.4 \%$ and a combined rate of minor and major stroke and procedure related death of $5 \% .{ }^{13}$ In contrast, there are little over 100 reported cases of endovascular intervention with primary stenting for extracranial vertebral artery stenosis. These early reports of selected non- randomised cases have shown high technical success rates, comparable to extracranial carotid stenting, with a complication rate of minor stroke or transient ischaemic attack (TIA) of only $3 \%$ and no related deaths during short term follow up. ${ }^{14-18}$ In the vertebral stenosis arm of the CAVATAS study, very few patients were randomised and the data have not been analysed to date.

We report the outcome after endovascular treatment for symptomatic vertebral artery stenosis in 14 patients who were followed up prospectively at a single centre between 1992 and 2001 .

\section{METHODS}

\section{Patient selection and characteristics}

Fourteen patients underwent vertebral balloon angioplasty (PTA) and stenting between 1992 and 2001 at Atkinson Morley's Hospital (St George's Hospital NHS Trust). All but one of the patients had symptomatic posterior circulation TIA or stroke, usually with recurrent symptoms despite maximum antiplatelet treatment. The antiplatelet regimen used was aspirin monotherapy in the earlier stages of the study, and combination treatment with aspirin and dipyradimole in the later stages. An episode of posterior circulation ischaemia was defined as the sudden onset of two or more symptoms attributable to the posterior circulation which, after adequate investigation, were presumed to be of a non-traumatic vascular origin. Vertebral stenosis was usually detected by colour Doppler ultrasound or magnetic resonance angiography, and confirmed by intra-arterial catheter angiography before any endovascular intervention.

In the one patient who had had symptoms attributable to anterior circulation ischaemia, computed tomography of the brain showed a left parietal infarct, and catheter angiography showed bilateral internal carotid artery occlusion, a normal 
Table 1 Characteristics of patients treated with vertebral percutaneous transluminal angioplasty or stenting, and immediate angiographic result

\begin{tabular}{|c|c|c|c|c|c|c|}
\hline Patient & Sex & $\begin{array}{l}\text { Age } \\
\text { (years) }\end{array}$ & Presenting symptom & $\mathrm{CT} / \mathrm{MRI}$ findings & $\begin{array}{l}\text { Angiographic findings } \\
\text { pretreatment }\end{array}$ & PTA (stent) result \\
\hline 1 & $M$ & 71 & Posterior circulation TIA & Bilateral cerebellar infarcts & LV: $80 \%$ stenosis & 0\% stenosis \\
\hline 2 & $\mathrm{~F}$ & 67 & Posterior circulation TIA & Normal & LV: $70 \%$ stenosis & $0 \%$ stenosis \\
\hline 3 & M & 54 & Anterior circulation stroke & Left parietal infarct & LV: $80 \%$ stenosis & $53 \%$ stenosis \\
\hline 4 & $\mathrm{~F}$ & 63 & Posterior circulation stroke & Left PICA infarct & RV: $50 \%$ stenosis & $32 \%$ stenosis \\
\hline 5 & $\mathrm{~F}$ & 61 & Posterior circulation stroke & Normal & LV: $80 \%$ stenosis & $0 \%$ stenosis (stent) \\
\hline 6 & M & 41 & Posterior circulation stroke & Right medullary infarct, left PCA infarct & RV: $80 \%$ stenosis & $10 \%$ stenosis (stent) \\
\hline 7 & $M$ & 39 & Posterior circulation stroke & Right PICA artery infarct & LV:70\% stenosis & $20 \%$ stenosis (stent) \\
\hline 8 & $\mathrm{~F}$ & 44 & Posterior circulation stroke & Bilateral PCA infarcts & LV: $80 \%$ stenosis & $40 \%$ stenosis (stent) \\
\hline 9 & $M$ & 59 & Posterior circulation stroke & Right pontine infarct & RV: $90 \%$ stenosis & $10 \%$ stenosis (stent) \\
\hline 10 & $M$ & 66 & Posterior circulation TIA & $\begin{array}{l}\text { Left pontine, bilateral cerebellar and } \\
\text { occipital infarcts }\end{array}$ & RV:70\% stenosis & O\%stenosis (stent) \\
\hline 11 & $M$ & 62 & Posterior circulation TIAs & Old right hemispheric infarct & LV: $70 \%$ stenosis & $0 \%$ stenosis (stent) \\
\hline 12 & M & 48 & Posterior circulation TIAs & Normal & $\begin{array}{l}\text { LV: } 80 \% \text { stenosis } \\
\text { R mid SCA: } 90 \% \text { stenosis }\end{array}$ & $\begin{array}{l}0 \% \text { stenosis (stent) } \\
50 \% \text { (PTA only) }\end{array}$ \\
\hline 13 & M & 67 & Posterior circulation stroke & Right occipital infarct & RV: $90 \%$ stenosis & $20 \%$ stenosis (stent) \\
\hline 14 & $\mathrm{~F}$ & 45 & Posterior circulation TIAs & Normal & LV $90 \%$ stenosis & $20 \%$ stenosis (stent) \\
\hline
\end{tabular}

F, female; ICA, internal carotid artery; LV, left vertebral; M, male; PCA, posterior cerebral artery; PICA, posterior inferior cerebellar artery; R, right; RV, right vertebral; SCA, subclavian artery; TIA, transient ischaemic attack.

right vertebral artery, $80 \%$ stenosis to the origin of the left vertebral artery, and patent posterior communicating arteries bilaterally. Left vertebral PTA was done in order to improve cerebral blood flow in both the anterior and the posterior circulations.

Table 1 shows the clinical presentation and angiographic findings of the patients undergoing endovascular intervention. The mean age of the group was 56 years (range 39 to 71 ). All subjects were white and nine were male. Seven were hypertensive, defined as having a history of raised blood pressure and on antihypertensive drug treatment or with a blood pressure of $\geqslant 160 \mathrm{~mm} \mathrm{Hg}$ systolic or $95 \mathrm{~mm} \mathrm{Hg}$ diastolic. ${ }^{19}$ Eleven had hypercholesterolaemia, defined as a fasting cholesterol level of more than $6 \mathrm{mmol} / \mathrm{l}$ or were already being treated with lipid lowering agents. These definitions used to categorise patients as hypertensive and hypercholesterolaemic were taken from the original CAVATAS criteria and were used throughout the series of patients for consistency. Eleven patients were current or ex-smokers. Two suffered from ischaemic heart disease. Two were diabetic. All were in sinus rhythm, with no cardioembolic source for their stroke. Seven had concomitant carotid artery stenosis of $>50 \%$. All patients were on treatment with 75 to $300 \mathrm{mg}$ of aspirin daily. Two patients were also taking $200 \mathrm{mg}$ of dipyramidole modified release twice daily, and one was also on treatment with warfarin.

Five patients were randomised to receive endovascular treatment in CAVATAS, while the remainder were treated according to physicians' consensus of best treatment. In the latter group, all patients had either recurrent symptoms in the vascular territory of a significantly stenosed vertebral artery ( $70 \%$ stenosis or more), or had posterior circulation ischaemic symptoms in the presence of a less severe stenosis occurring in a dominant vertebral artery (the other being atretic or occluded), with no patent posterior communicating artery on the side of the stenosis seen on catheter angiography.

CAVATAS received approval from the local hospital ethics committee, and written informed consent was obtained from all patients by the treating neuroradiologist. The first five patients underwent follow up catheter angiography at one year. More recently treated patients were followed up with vertebral artery colour Doppler ultrasound examination. If the peak systolic velocity in the vertebral artery was recorded as being greater than $0.8 \mathrm{~m} / \mathrm{s}$, catheter angiography was then done. Restenosis was defined as an increase in stenosis at one year to more than $50 \%$, using the method described below. Patients were followed up by a neurologist immediately after the procedure, at one and six months after the procedure, and then at annual intervals.

\section{PTA procedure}

All endovascular procedures were undertaken under local anaesthesia by a single interventional neuroradiologist (AC). The degree of vertebral artery stenosis was determined from the catheter angiogram using the following formula:

$$
\% \text { stenosis }=100(1-\mathrm{A} / \mathrm{V})
$$

where $\mathrm{A}$ is the diameter of the residual lumen at the point of maximum stenosis, and $\mathrm{V}$ is the width of disease free distal vertebral artery at the point where the walls were approximately parallel. This is similar to the method used to measure carotid stenosis in the North American symptomatic carotid endarterectomy trial. ${ }^{20} \mathrm{~A} 6 \mathrm{~F}$ sheath was inserted percutaneously under local anaesthesia into the right femoral artery, or, in two of the 14 patients, through a brachial puncture. A $6 \mathrm{~F}$ guiding catheter was then inserted into the subclavian artery over an exchange wire. Under roadmapping and after intravenous anticoagulation with heparin, the stenosis was crossed with a 0.014 inch $(0.35 \mathrm{~mm})$ wire. In the first four patients treated by simple balloon angioplasty, a 3-4 mm angioplasty balloon (with a diameter less than that of the distal disease-free vertebral artery) was then placed across the stenosis and inflated to $8 \mathrm{~atm}$ using a standard pressure inflation device. Inflation was maintained for about 15 seconds. The balloon was deflated and the degree of residual stenosis was viewed angiographically. The dilatation was repeated up to three times. In the four patients treated by balloon angioplasty alone, $300 \mathrm{mg}$ of aspirin daily was given for at least one week before the procedure and continued indefinitely after discharge.

In the 11 patients in whom a stent was deployed, a guiding catheter was exchanged into the subclavian artery. Through this guiding catheter, a balloon expandable stent loaded over a 0.014 inch wire (Medtronic ${ }^{\mathrm{TM}}$ AVE INX, or previously S670 and AVE coronary stents) was introduced through the guiding catheter. After guiding the wire through the stenosis on roadmapping, the stent was placed (still under roadmapping) across the stenosis with the proximal end positioned at the origin of the vertebral artery from the subclavian artery. The stent was deployed at the same time as the stenosis was dilated by inflation of the angioplasty balloon. This procedure was also done under anticoagulation with heparin, which was continued for a further 24 hours afterwards. All the patients 
Table 2 Angiographic findings of per cent stenosis before percutaneous transluminal angioplasty (PTA), immediately after and at one year follow up

\begin{tabular}{llll}
\hline $\begin{array}{l}\text { Patient and } \\
\text { vertebral artery }\end{array}$ & Pre-PTA (\%) & PTA result (\%) & $\begin{array}{l}\text { One follow up } \\
(\%)\end{array}$ \\
\hline 1: left & 80 & 0 & 70 \\
2: left & 70 & 0 & 70 \\
3: left & 80 & 53 & 75 \\
4: right & 50 & 32 & $70^{*}$ \\
\hline
\end{tabular}

*Patient developed symptoms and was retreated using PTA with stenting.

were treated with $300 \mathrm{mg}$ aspirin daily, and a second antiplatelet agent (either dipyramidole $100 \mathrm{mg}$ three times daily plus dipyramidole MR $200 \mathrm{mg}$ twice daily, or clopidigrel $75 \mathrm{mg}$ once a day) was routinely prescribed for one week before stenting and for one to three months after the procedure. Thereafter patients were maintained on aspirin monotherapy unless they developed further symptoms during follow up.

\section{RESULTS}

\section{Balloon angioplasty alone group}

The first four patients treated with simple balloon angioplasty were followed up for a mean of 68.5 months (range 60 to 76). Vessel dilatation was achieved in all patients, with a mean improvement in stenosis from 73 (18)\% before treatment to 21 $(26) \%$ after treatment $(\mathrm{p}=0.059$; paired $t$ test $)$. None of the patients had a major complication during or immediately after PTA, and none had a TIA or stroke within 30 days of the procedure. One patient had a brachial haematoma which resolved spontaneously. Follow up catheter angiography at one year showed restenosis of the PTA site in all patients, with a mean degree stenosis at one year of $71 \%$ (table 2), although all the patients remained asymptomatic at that time (fig 1 ).

During further follow up, one patient had a posterior circulation TIA 18 months after the initial PTA. This patient was retreated with vertebral artery primary stenting with an excellent anatomical result (fig 2). The patient remains asymptomatic, and colour Doppler ultrasound has not shown any restenosis five years after stent insertion. The three other patients treated by simple balloon angioplasty subsequently had no further symptoms of posterior circulation ischaemia. However, two of the patients died during follow up-one died five years after the procedure from ischaemic heart disease and the other, more than five years after the procedure from pneumonia.

\section{Primary stenting group}

Ten patients (Nos 5-14) were treated by primary stenting and have been followed up for a mean of 19.7 months (range 1 to 48). All stenoses were treated successfully, with a mean improvement in angiographic stenosis severity from $82(8) \%$ before treatment to $13(13) \%$ after treatment $(p<0.001$; paired $t$ test). One patient experienced two posterior circulation TIAs, each lasting less than five minutes, 72 hours after stenting. Thus the risk of TIA after stenting in this series was $20 \%$. There were no other immediate or early complications. Follow up colour Doppler ultrasound examination showed evidence of restenosis in only one case, six months after the procedure, which was found to be a 55\% stenosis on catheter angiography. The patient remained asymptomatic and subsequent colour Doppler ultrasound examinations, including the latest scan done three years after stenting, have shown normal velocities. None of the stented patients has reported posterior circulation stroke symptoms during the prospective follow up. Two patients had right middle cerebral
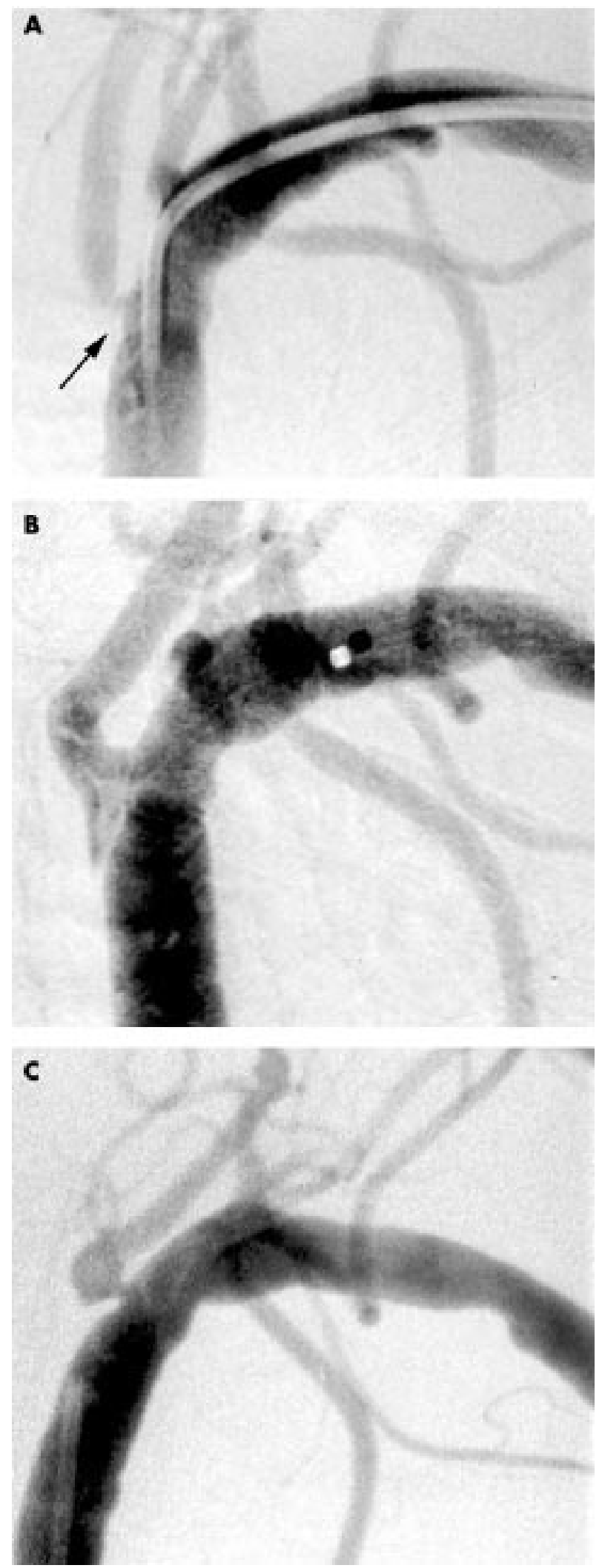

Figure 1 Digital subtraction angiograms in a patient showing $(A)$ severe vertebral artery origin stenosis before treatment, (B) successful vessel dilatation immediately after balloon angioplasty, and (C) severe restenosis at follow up angiography one year later.

artery territory strokes, six and 18 months, respectively, after stenting. Both events were attributable to coexistent carotid disease. One patient died as a result of the stroke. Another 


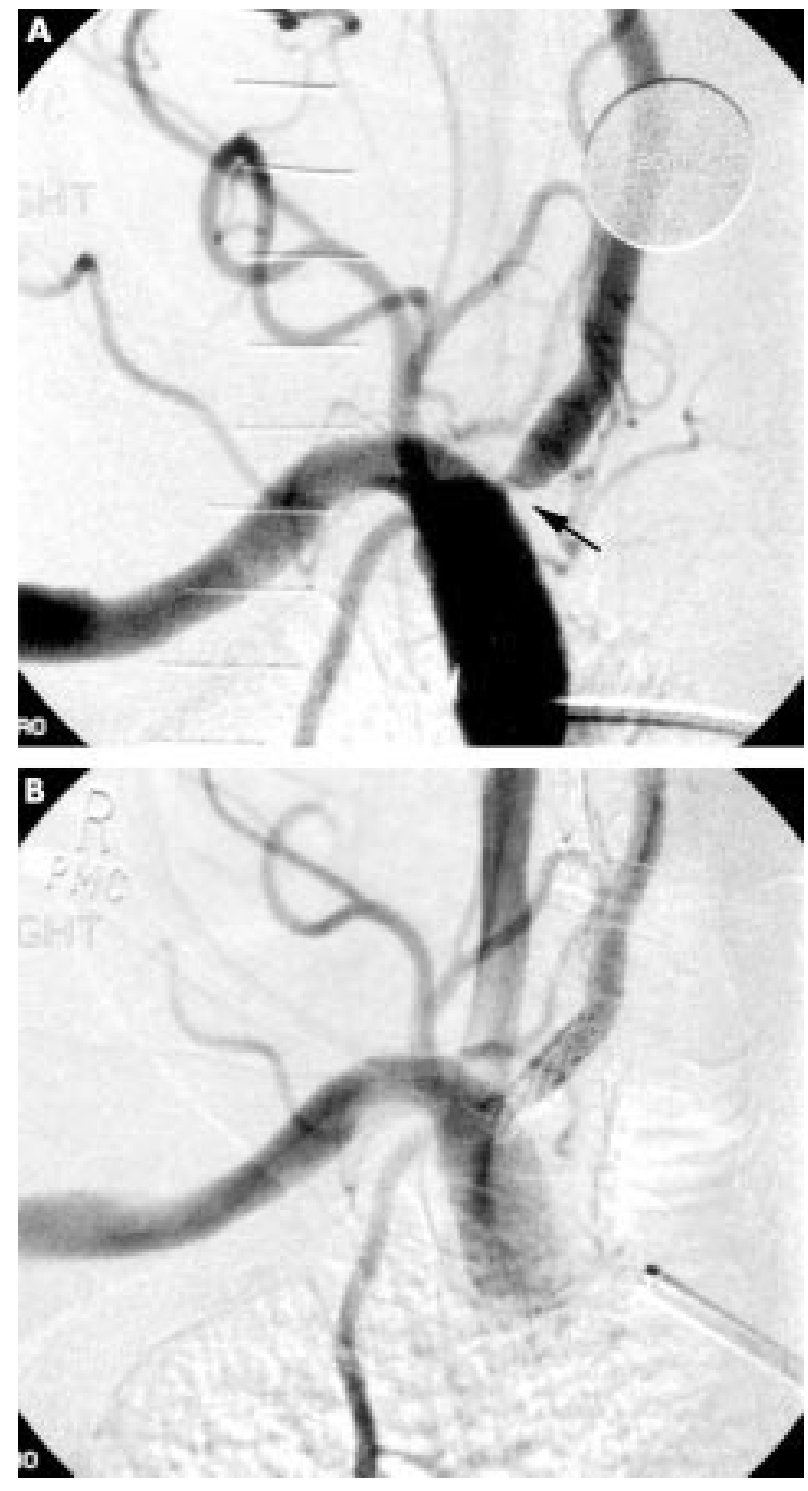

Figure 2 (A) Digital subtraction angiogram showing vertebral artery origin restenosis 18 months after initial angioplasty treatment, and (B) successful vessel dilatation after repeat vertebral artery angioplasty and insertion of a stent.

patient with a history of ischaemic heart disease died five months after the procedure from myocardial infarction.

\section{DISCUSSION}

This series shows that balloon angioplasty and stenting can both be successfully and safely undertaken in individuals with atherosclerotic vertebral artery origin stenosis with a very low complication rate. None of our patients developed a stroke or died within 30 days of the procedure and none had a posterior circulation stroke during follow up. However, restenosis after balloon angioplasty had occurred in all four patients treated without stenting by one year. In contrast, only one of 11 arteries in which a stent was deployed showed restenosis over an average of 20 months of follow up. In addition, primary stenting resulted in a greater initial improvement in the degree of stenosis in comparison with balloon angioplasty alone. Although the balloon angioplasty alone and primary stenting groups were assessed for restenosis using different imaging methods, good views of the vertebral artery origin stents were obtained with colour Doppler ultrasound in all patients during the follow up. The duration of follow up differed in the two groups, making direct comparisons difficult, but the results nevertheless suggest that stenting may have better long term results.

The rate of restenosis after endovascular treatment of vertebral artery stenosis varies between series. Storey et al reported that all three patients who underwent vertebral PTA developed symptomatic restenosis within three months. ${ }^{21}$ Stenting was subsequently undertaken and follow up catheter angiography in two of these patients showed no restenosis three months and one year after stent insertion. Higashida et al used a combination of Doppler ultrasound, magnetic resonance angiography, and catheter angiography to follow up patients after proximal vertebral artery PTA and showed restenosis in only three of 34 patients (9\%) in their series. ${ }^{22}$ However, the proportion of patients who had vertebral artery origin stenosis rather than more distal vessel disease was not specified in that series.

Chastain et al have followed up the largest reported series of patients after extracranial vertebral artery stent placement for the treatment of symptomatic (>60\%) vertebral artery stenosis. ${ }^{14}$ Forty four of 49 patients underwent angiographic follow up at six months, and 48 of the 55 vessels treated (87\%) had involvement of either the origin or proximal extracranial vertebral artery. A moderate degree of restenosis $(27.3$ (19.6)\%) was seen in five vessels-that is, in $10 \%$ of treated vessels. These results are in keeping with results of our series, with a low restenosis rate after primary stenting for vertebral artery origin stenosis.

Our experience suggests that the outcome after treatment of vertebral artery origin stenosis is similar to that seen after endovascular treatment of renal artery ostial stenosis. Conventional angioplasty in the latter group has a high failure rate owing to elastic recoil and the condition is better managed by stenting. ${ }^{23}$

The results of our case series suggest that, from a technical viewpoint, primary stenting for vertebral artery atherosclerotic stenosis at the vessel origin has a high success rate and a low complication rate. In the light of the advances in secondary preventive treatment for stroke patients over the past decade, data from well designed randomised clinical trials are required to compare the outcome after endovascular treatment with best medical care alone in this patient population. Before a definitive trial, further data from an intermediate sized pilot study are required to determine sample size calculations.

\section{ACKNOWLEDGEMENTS}

This research was partly funded by grants from the British Heart Foundation, the NHS Management Executive, and the Stroke Association. The ultrasound laboratory was established with a grant from the Welcome Trust. GCC is a Stroke Association clinical research fellow. Diana Colquhoun assisted with the ultrasound examinations.

\section{Authors' affiliations}

G C Cloud, H S Markus, Division of Clinical Neuroscience, St George's Hospital Medical School, London SW17 ORE, UK

A Clifton, Department of Neuroradiology, Atkinson Morley's Hospital, London SW20 ONE

F Crawley, D J H McCabe, M M Brown, Institute of Neurology, University College London, London WC1N 3BG

Competing interests: MMB has received travel reimbursements for attending conferences from Boston Scientific and research grant funding, speakers fees and educational fees from Sanofi-Synthelabo. None of the other authors has competing interest to declare.

\section{REFERENCES}

1 Bamford J, Sandercock P, Dennis $M$, et al. Classification and natural history of clinically identifiable subtypes of cerebral infarction. Lancet 1991;337:1521-6.

2 Bogousslavsky J, van Melle G, Regli F. The Lausanne Stroke Registry: analysis of 1000 consecutive patients with first stroke. Stroke 1988; 19:1083-92 
3 Hass WK, Fields WS, North RR, et al. Joint study of extracranial arterial occlusion. II. Arteriography, techniques, sites, and complications. JAMA 1968;203:961-8.

4 Caplan LR, Amarenco P, Rosengart A, et al. Embolism from vertebral artery origin occlusive disease. Neurology 1992;42:1505-12.

5 Koroshetz WJ, Ropper AH. Artery-to-artery embolism causing stroke in the posterior circulation. Neurology 1987;37:292-5.

6 Pessin MS, Daneault N, Kwan ES, et al. Local embolism from vertebral artery occlusion. Stroke 1988;19:112-15.

7 Wityk RJ, Chang HM, Rosengart A, et al. Proximal extracranial vertebral artery disease in the New England Medical Center Posterior Circulation Registry. Arch Neurol 1998;55:470-8.

8 Berguer R. Vertebrobasilar ischaemia: indications, techniques, and results of surgical repair. In: Rutherford RB, ed. Vascular surgery, 5th ed. Philadelphia: WB Saunders Co, 2000:1823-37.

9 Deriu GP, Ballotta E, Franceschi L, et al. Surgical management of extracranial vertebral artery occlusive disease. J Cardiovasc Surg (Torino) 1991;32:413-19.

10 Edwards WH, Mulherin JL. The surgical reconstruction of the proximal subclavian and vertebral artery. J Vasc Surg 1985;2:634-42.

11 Spetzler RF, Hadley MN, Martin NA, et al. Vertebrobasilar insufficiency. Part 1 . Microsurgical treatment of extracrania vertebrobasilar disease. J Neurosurg 1987;66:648-61.

12 Trial Participants. Endovascular versus surgical treatment in patients with carotid stenosis in the carotid and vertebral artery transluminal angioplasty study (CAVATAS): a randomised trial. Lancet 2001;357:1729-37

13 Wholey MH, Wholey M, Mathias K, et al. Global experience in cervical carotid artery stent placement. Cathet Cardiovasc Intervent 2000;50:160-7.
14 Chastain HD, Campbell MS, lyer S, et al. Extracranial vertebral artery stent placement: in-hospital and follow-up results. J Neurosurg 1999;91:547-52.

15 Jenkins JS, White CJ, Ramee SR, et al. Vertebral artery stenting. Cathet Cardiovasc Intervent 2001:54:1-5.

16 Malek AM, Higashida RT, Phatouros CC, et al. Treatment of posterior circulation ischemia with extracranial percutaneous balloon angioplasty and stent placement. Stroke 1999;30:2073-85.

17 Piotin M, Spelle L, Martin JB, et al. Percutaneous transluminal angioplasty and stenting of the proximal vertebral artery for symptomatic stenosis. Am J Neuroradiol 2000:21:727-31.

18 Mukherjee D, Roffi M, Kapadia SR, et al. Percutaneous intervention for symptomatic vertebral artery stenosis using coronary stents. J Invasive Cardiol 2001;13:363-6.

19 WHO Subcommittee. Summary of 1993 World Health Organisation-International Society of Hypertension guidelines for the management of mild hypertension. Subcommittee of WHO/ISH mild hypertension liaison committee. BM 1993;307:1541-6.

20 Trial Collaborators. Beneficial effect of carotid endarterectomy in symptomatic patients with high-grade carotid stenosis. North American symptomatic carotid endarterectomy trial collaborators. N Engl J Med 1991;325:445-53

21 Storey GS, Marks MP, Dake M, et al. Vertebral artery stenting following percutaneous transluminal angioplasty. Technical note. J Neurosurg 1996;84:883-7.

22 Higashida RT, Tsai FY, Halbach VV, et al. Transluminal angioplasty for atherosclerotic disease of the vertebral and basilar arteries. J Neurosurg 1993;78:192-8.

23 Van De Ven PJ, Beutler JJ, Kaatee R, et al. Transluminal vascular stent for ostial atherosclerotic renal artery stenosis. Lancet 1995;346:672-4. 